\title{
Hemorajik ve İskemik Serebrovasküler Hastalık Tanısı Alan Hastalarda Kan Laktat Düzeyinin Prognoz Üzerine Etkisi
}

The Effect of Blood Lactate Level on Prognosis in Patients with Hemorrhagic and Ischemic Cerebrovascular Disease

${ }^{1}$ Department of Emergency Medicine, Eskisehir Osmangazi University Medical Center, Eskisehir, Turkey

${ }^{2}$ Department of Neurology, Eskisehir Osmangazi University Medical Center, Eskisehir, Turkey
Correspondence:

Engin ÖZAKIN

Department of Emergency Medicine, Eskisehir Osmangazi University Medical Center, Eskisehir, Turkey e-mail: enginozakin@hotmail.com
${ }^{1}$ Turgay Çağlayan, ${ }_{\oplus}^{1}$ Engin Özakın, ${ }^{2}$ Atilla Özcan Özdemir, ${ }^{1}$ Nurdan Acar, ${ }^{1}$ Mustafa Emin Çanakçı, ${ }^{1}$ Ebubekir Arslan, 'Hakan Dolgun, Filiz Baloğlu Kaya

\section{Özet}

Calışmamızın amacı iskemik ve hemorajik inme tanısı alan hastalarda, venöz kan laktat değerinin prognoz üzerine etkisinin arastırılmasıdır. Çalışmamıza, (Eskişehir Osmangazi Üniversitesi Tip Fakültesi cil servisine başvuran ve 12 saatten kısa süreli iskemik veya hemorajik inme tanısı alan 18 yaş üstü hastalar dahil edildi. Hastaların demografik bilgileri, ilk başvuru ve 24. saat venöz kan laktat düzeyleri ve) National Institutes of Health Stroke Scale (NIHSS), bilgisayarl tomografi (BT) bulguları ve 3. ay modifiye Ranson skalası (mRs) kayıt edildi ve aralarındaki ilişki değerlendirildi. Çalışmaya 51’i (\%58) erkek, 72'si (\%81,8) iskemik, inme tanısı alan toplam 88 hasta dahil edildi. İskemik inme tanısı alan 7 (\%8) hastada infarkt alanı 2/3'den büyük olduğu çekilen BT’de görüldü. Başvuru ve 24. saat venöz kan laktat düzeyleri medyan değerleri sırasıyla: 1,6 mmol/L, 1,4 mmol/l ve azalma istatistiksel olarak anlamlı idi (0-24 Saat p=0,019, $\mathrm{p}<0,001)$.İskemik inmeli hastalarda ilk venöz kan laktat düzeyi, infarkt alanı büyüklüğü MCA sulama alanının 2/3'ünden büyük olanların, küçük olanlara göre daha yüksek idi $(p=0,013)$. Hemorajik inmelerde ise ilk başvuru venöz kan laktat düzeylerinin iskemik inmeye göre daha yüksek idi $(2.05 \mathrm{e}$ karşı1 $1,55 \mathrm{mmol} / \mathrm{l}, \mathrm{p}=0,043)$. Başvuru ve 24 . saat laktat düzeyleri ile NIHSS ve mRs arasında anlamlı ilişki tespit edilemedi. İnme hastalarında venöz kan laktat düzeyi ölçümü, kanama tipi ve iskemik infarkt alanı büyüklüğünün belirlenmesinde ve inme yönetiminde acil tıp hekimlerine yardımcı olabilir.

Anahtar Kelimeler: İnme, laktat, venöz, prognoz, iskemik, kanama

\section{Abstract}

The aim of our study is to investigate the relationship between venous blood lactate levels and prognosis in ischemic and hemorrhagic stroke patients. Patients over 18 years of age who applied to Eskişehir Osmangazi Univesrsity Faculty of Medicine emergency service and diagnosed with ischemic or hemorrhagic stroke for less than 12 hours were included in our study. The demographic information of the patients, initial and 24th hour venous blood lactate levels and National Institutes of Health Stroke Scale (NIHSS), Computed Tomography (CT) findings and 3rd month modified Rankin scale (mRs) were recorded and the relationship between them was evaluated. A total of 88 patients, $51(58 \%)$ male, $72(81.8 \%)$ diagnosed with ischemic stroke, were included in the study. In $7(8 \%)$ patients diagnosed with ischemic stroke, the infarct area larger than $2 / 3$ was seen on CT. The median values of venous blood lactate levels at admission and 24 hours were $1.6 \mathrm{mmol} / \mathrm{L}, 1.4 \mathrm{mmol} / \mathrm{L}$, respectively and the decrease was statistically significant $(0-24$ Hours $\mathrm{p}=0.019, \mathrm{p}<0.001)$. In patients with ischemic stroke, the first venous blood lactate level was higher in those with infarct size greater than $2 / 3$ of the MCA irrigation area compared to the smaller ones $(p=0.013)$. In hemorrhagic strokes, initial venous blood lactate levels were higher than in ischemic stroke (2.05 vs $1.55 \mathrm{mmol} / \mathrm{l}, \mathrm{p}=0.043)$. No significant correlation was found between NIHSS and mRs with lactate levels at admission and 24 hours. Measurement of venous blood lactate level in stroke patients can assist emergency physicians in determining the type of bleeding and the size of the ischemic infarct site and in stroke management.

Keywords: Stroke, lactate, NIHSS, mRs 


\section{Giriş}

İskemik ve hemorajik serebrovasküler hastalıklar, tüm dünyada önemli bir morbidite ve mortalite nedenidir (1). İskemik inmelerin yaklaşık\% 8'i ölümle sonuçlanır (2). Buna göre, iskemik inme sonras1 sonucun doğru öngörücülerini belirlemek önemlidir.

Laktat, anaerobik metabolizmanın bilinen bir yan ürünüdür ve hipoperfüzyon durumlarında yükselir. Global hipoperfüzyon sırasında laktat üretiminin metabolizma hızını aştığı ve kan laktat düzeyinin arttı̆̆ iyi bir şekilde belgelenmiştir. Hiperlaktatemi, metabolik stres yanıtının bir belirteci olarak kabul edilir ve kritik hastalarda artmış mortalite ile ilişkilidir (3-5). Manyetik rezonans (MR) spektrometresi ve mikrodiyaliz kullanan önceki birkaç çalışmada, laktatın akut inme hastalarında iskemik beyin lezyonlarında biriktiği gösterilmiştir (6,7). Brouns ve arkadaşları ise beyin omurilik sıvısındaki laktatın akut iskemik inmede metabolik kriz için bir belirteç olduğunu tespit etmişlerdir (8). Yapılan sınırlı sayıda klinik çalışma ve hayvan deneylerinde laktatın hasarlı ve iskemik beyin dokusunda enerji kaynağ 1 olarak kullanıldığ 1 ve nöroprotektif etkisinin olduğu gösterilmiştir (9-12). Buna karşın laktatın prognozla ilişkili olmadığını belirtir çalışmalar da mevcuttur $(8,13)$.

Çalışmamızda acil serviste serebrovasküler hastalık tanısı alan hastalarda başvuru ve klinik takibi sırasında ölçülen kan laktat düzeyinin prognoz üzerine etkisini ortaya koymayı amaçladık.

\section{Amaç ve Yöntem}

Bu çalışma Eskişehir Osmangazi Üniversitesi Tıp Fakültesi Hastanesi Acil Servisi'nde Etik Kurul onayından sonra (Etik Kurul onay tarihi ve say1s1: 27 Kasim 2014/ 06) 01.12.201430.11.2015 tarihleri arasında başvuran, 12 saatten kısa süreli hemorajik veya iskemik serebrovasküler hastalık tanısı alan hastalarda yapılmıştır. İleriye dönük ve tanımlayıcı bir çalışmadır. Çalışmaya katılan hastalara Helsinki Bildirgesine göre hazırlanan " Hasta Bilgilendirme Formu" ve "Hasta Onam Formu" okutulmuş ve imzalı onamları alınmıştır. Bilinci açık olmayan hastaların yakınlarından onam alınmıştır. Çalışmaya dahil edilme kriterleri; 18 yaş ve üstü ve hemorajik ve iskemik serebrovasküler hastalık, dışlama kriterleri ise gebe, travmaya bağlı serebrovasküler patoloji, arka sistem kaynaklı inme, venöz sistem kaynaklı hemorajik inme, malignite, onam olmamas1, ve nöbet olarak kabul edildi. Çalışmaya, araştırmanın yapıldığ 1 01.12.2014-30.11.2015 tarihleri arasında Eskişehir Osmangazi Üniversitesi Tıp Fakültesi Hastanesi Acil Servisi' ne başvuran, iskemik ve hemorajik inme tanısı almış toplam 88 hasta dahil edilmiştir.

Her hasta acil serviste kıdemli acil tıp asistanı ve nöroloji konsültanı tarafindan değerlendirildi. Hastaların yaş, cinsiyet gibi demografik verileri yanı sıra, geliş vital bulgular1 (tansiyon, nabiz, solunum sayıs1, ateş ve satürasyon), özgeçmişi (TOAST sinıflamasına göre), kullandığı ilaçlar, alışkanlıkları kayıt edildi. Kan laktat ölçümleri venöz kandan hastaların acil servise ilk kabulünden 5 dakika sonra ve 24.cü saatlerde alındı. Ayrica hastaların serebrovasküler hastalık tipi (iskemik/hemorajik), başvuru ve/veya kontrol beyin BT, ilk başvuru ve 24.saat National Institutes of Health Stroke Scale (NIHSS) skoru kayıt edildi

Beyin bilgisayarlı tomografi (BT) çekimleri genel radyolojik çekim kurallarına uygun olarak hastanın başvurusunda ve yattığı servisteki takibinde yapıldı. Görüntüleme yorumları inme konusunda uzmanlaşmış, tek bir nörolog hekim tarafindan yapıldı. Görüntüleme yorumunu yapan kişi hastaların klinik ve laboratuvar sonuçlarından habersizdi.

\section{Istatistiki Yöntem}

Analizlerin uygulanmasinda IBM SPSS Statistics 21.0 programından yararlanılmıştır. Sürekli veriler Ortalama \pm Standart Sapma olarak verilmiştir. Kategorik veriler ise yüzde (\%) olarak verilmiştir. Verilerin normal dağılıma uygunluğunun araştırılmasında Shapiro Wilk testinden yararlanılmıştır. Farklı ölçüm zamanlarındaki değerlerin 
karşılaştırılmasında, grup sayısı iki olduğu durumda Wilcoxon testi, grup sayısi üç ve üzerinde olduğu durumlarda ise Friedman's testi kullanılmıştır. Tekrarlı ölçümler için iki yönlü tekrarlı ölçümler ANOVA (Tek Faktör Tekrarl1) "Two way reapeated mesasures ANOVA (One Factor Repetition)" testi kullanılmıştır. Değişkenler arası ilişkinin (korelasyon) yönü ve büyüklüğünün belirlenmesi normal dağılıma uygunluk göstermeyen değișkenler için ise Spearman korelasyon katsayıları hesaplanmıştır. İstatistiki değerlendirmede elde edilen $\mathrm{p}$ değerinin 0.05 değerlerinden küçük olması anlamlı kabul edilmiştir. Veri setindeki dağılımı Q1 ve Q3 1.ci ve 3. çeyreklikleri göstermektedir

\section{Bulgular}

Çalışmaya dahil edilen 51'i (\%58) erkek, toplam 88 serebrovasküler olay (SVO) ile acil servise başvuran hastaların yaş ortalamas 165 $( \pm 12,21$; minimum-maksimum: 28-82) idi. Çekilen beyin BT'lerine göre hastaların 16's1 hemorajik (10'u erkek), 72'si (41'i erkek) iskemik olarak değerlendirildi ve cinsiyet ile SVO arasında ilişki tespit edilmedi (p: 0.684). Hastaların özgeçmişlerine bakıldığında; 48'inde (\%54,5) hipertansiyon, 26'sinda, (\%29.5) diyabet, 17'sinde $(\% 19,3)$ aterosklerotik kalp hastalığı, 13 'ünde $(\% 14,8)$ kalp yetmezliği ve 13'ünde $(\% 14,8)$ AF olduğu görüldü. İlaç kullanımına bakıldığında; hastaların \%45,5'inin $(\mathrm{n}=40)$ antihipertansif, $\% 25$ 'inin $\quad(n=22)$ oral antidiyabetik, \%5,7'inin $(\mathrm{n}=5)$ insülin, $\% 22,7$ 'sinin $(n=20)$ antiagregan, \%1,1'i $(n=1)$ oral antikoagülan, \%3,4'ünün $(\mathrm{n}=3)$ heparin, $\% 10,2$ 'sinin $(\mathrm{n}=9)$ antiaritmik ilaç kullandığ 1 görüldü. Hastaların \%17' si $(n=15)$ sigara, $\% 1,1$ 'i $(n=1)$ alkol kullanmakta idi. Hastaların acil servise ilk geliş vital bulgu ve değişkenlerinin analizi tablo 1'de verilmiştir. Etiyolojik olarak değerlendirme şekil 1'de verilmiştir. Başvuru beyin BT değerlendirmesinde hastaların \%81,8'inde $(\mathrm{n}=72)$ iskemik inme tespit edildi. İnfarkt alanı \%63,6'sinda ( $\mathrm{n}=56)$ (Orta serebral arter) MCA sulama alanının 1/3'ünden küçük, $\% 10,2$ 'sinde $(\mathrm{n}=9)$ MCA sulama alanının 1/3'ü ile 2/3'ü arasında, $\% 8$ 'inde $(n=7)$ MCA sulama alanının 2/3'ünden büyük idi. Hastaların \%18,2'sinde $(n=16)$ hemorajik inme tespit edilirken; \%13,6'sinde $(n=12)$ intraparankimal kanama, \%4,5'inde $(n=4)$ SAK tespit edildi.

Tablo 1. Geliş Vital Bulguları, Skorlama ve Laboratuvar Değerlerinin Medyan ve Çeyreklik Değerleri

\begin{tabular}{|c|c|c|}
\hline & Medyan (n:88) & Q1-Q3 \\
\hline \multicolumn{3}{|l|}{ Vital bulgular } \\
\hline Sistolik arter basıncı (mmHg) & 150 & $130-170$ \\
\hline Diyastolik arter basıncı (mmHg) & 90 & $80-100$ \\
\hline Nabız (vuru/dakika) & 85 & $73-98$ \\
\hline Solunum sayısı (/dakika) & 20 & $18-20$ \\
\hline Satürasyon (\%) & 96 & $94-97$ \\
\hline \multicolumn{3}{|l|}{ Klinik Skorlama } \\
\hline İlk bașvuru NIHSS & 5 & $3-18$ \\
\hline 24. saat NIHSS & 2 & $2-12$ \\
\hline Glaskow Koma Skoru & 15 & $12-15$ \\
\hline \multicolumn{3}{|l|}{ Laboratuvar Değerleri } \\
\hline Laktat - İlk bașvuru (mmol/l) & 1,6 & $1,3-2,3$ \\
\hline Laktat - 24.saat (mmol/l) & 1,4 & $1,1-2$ \\
\hline Glukoz (mg/dl) & 139 & $113-192,5$ \\
\hline
\end{tabular}




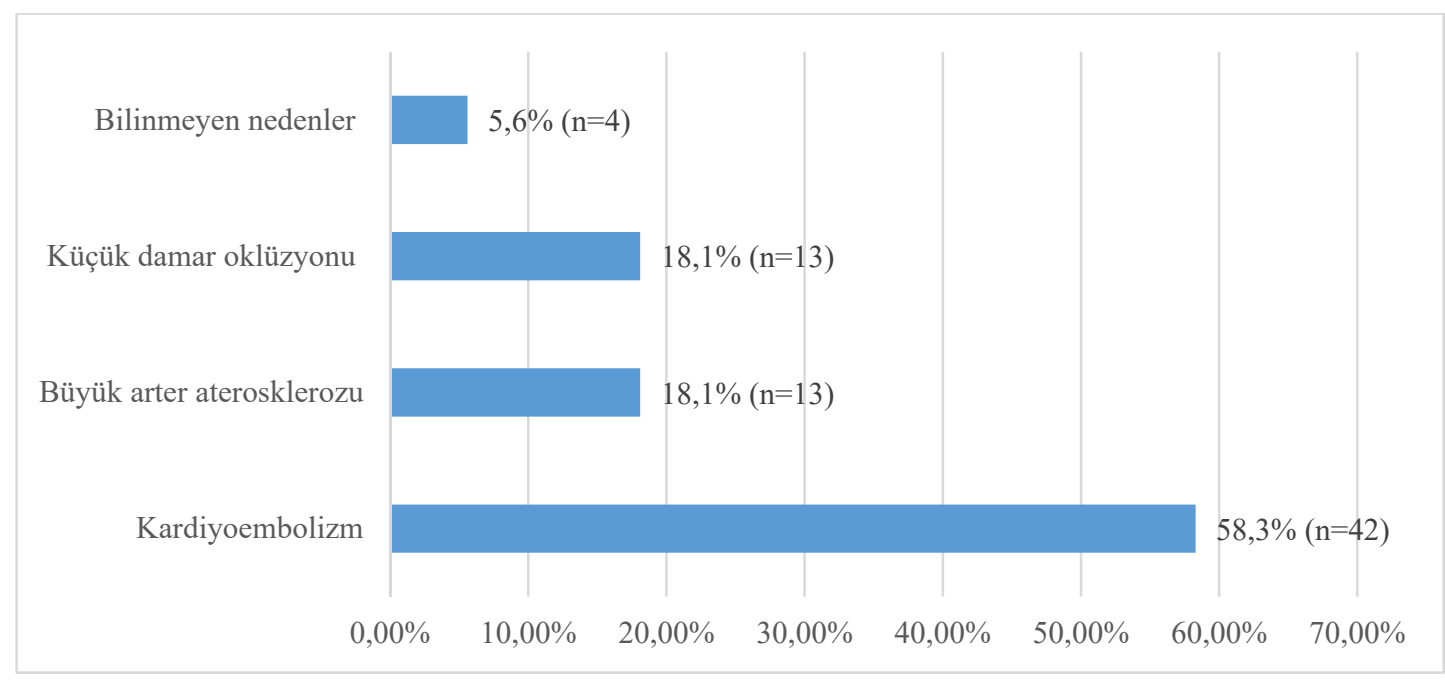

Şekil 1. İnme hastalarının etiyolojik olarak sınıflaması

Çalışmaya dahil edilen 88 hastanın laktat değerleri incelendiğinde başvuru ile 24. saat arasında kan laktat değerleri arasında anlamlı fark olduğu ve zaman ile kan laktat değerlerinde azalma olduğu görülmüştür $(\mathrm{p}<0,001)$. Hastaların NIHS skorları medyan değeri 5, 24 saatteki medyan değerleri 2 olarak hesaplandı ve ilk başvuru ve 24 saat NIHSS karşılaştırılmasında anlamlı fark tespit edildi $(\mathrm{p}<0.001)$.
Çalışmaya dahil edilen hastaların \%12,5 $(\mathrm{n}=11)^{\prime}$ inde $0,9 \mathrm{mg} / \mathrm{kg}$ dozunda alteplaz kullanılarak intravenöz trombolitik tedavi verilirken, $\% 8 \quad(\mathrm{n}=7)$ 'inde endovasküler girişim yapıldı.

İnme tipi açısından laktat düzeylerine bakıldığında hemorajik inmelerde başvuru ile 24. saat laktat düzeylerinin iskemik inmeye göre daha yüksek olduğu ve bu farkın istatistiksel olarak anlamlı olduğu görüldü $(\mathrm{p}=0,005)$ (Tablo 2).

Tablo 2. Kan laktat ve SVO tipi arası ilişki

\begin{tabular}{llll}
\hline Değiş̧enler & İskemik inme & Hemorajik inme & $\mathbf{p}^{*}$ \\
& $\mathbf{N}: \mathbf{7 2}$ & N: 16 & \\
\hline Laktat (ilk başvuru) $\mathbf{m m o l} / \mathbf{l}$ & Medyan (Q1-Q3) & Medyan (Q1-Q3) & \\
\hline \multirow{2}{*}{ Laktat (24. Saat) $\mathbf{m m o l} / \mathbf{l}$} & $(1,55$ & 2,05 & 0,043 \\
& 1,4 & $(1,4-2,97)$ & 0,045 \\
\hline
\end{tabular}

"Mann-Whitney U test, Q1-Q3: 1. ve 3. çeyreklikler arası olarak tanımlanmıştır

İskemik inmeler ele alındığında infarkt boyutu ile laktat arası ilişkinin karşılaştırmasında infarkt alanı MCA sulama alanının 2/3'ünden büyük olması durumunda, infarkt alanının 2/3'ünden küçük olan hastalara göre ilk başvuru ve 24. saat kan laktat düzeyi yüksek tespit edildi (Tablo 3)

Tablo 3. İskemik İnmeli hastalarda infarkt alanı ve laktat düzeyi arası ilişki

\begin{tabular}{llll}
\hline Değişkenler & İnfarkt alanı $<\mathbf{2 / 3}$ & İnfarkt alanı $>\mathbf{2 / 3}$ & $\mathbf{P}^{*}$ \\
& $\mathbf{N}: \mathbf{6 5}$ & $\mathbf{N}: \mathbf{7}$ & \\
& Medyan (Q1-Q3) & Medyan (Q1-Q3) & \\
\hline Laktat (ilk başvuru) $\mathbf{m m o l} / \mathbf{l}$ & 1,4 & 2,5 & 0,013 \\
Laktat (24. Saat) $\mathbf{m m o l} / \mathbf{l}$ & $(1,2-1,9)$ & $(1,6-3.5)$ & 0,039 \\
\hline
\end{tabular}

"Mann-Whitney U test, Q1-Q3: 1. ve 3. çeyreklikler arası olarak tanımlanmıştır 
İskemik inme hastaları ele alındığında değeri karşılaştırıldığında istatistiksel olarak başvuru ile 24. saat NIHSS ile kan laktat anlamlı fark gözlenmedi (Tablo 4).

Tablo 4. İskemik İnme Hastaları İçin Laktat ve NIHSS İlişkisi

\begin{tabular}{lll}
\hline Değişkenler & NIHSS başvuru & NIHSS 24.saat \\
\hline Laktat (ilk başvuru) mmol/l & $\mathrm{p}=0,253, \mathrm{r}=0,136$ & $\mathrm{p}=0,135, \mathrm{r}=0,178$ \\
Laktat (24. Saat) mmol/l & $\mathrm{p}=0,192, \mathrm{r}=0,156$ & $\mathrm{p}=0,259, \mathrm{r}=0,135$ \\
\hline Spearman's test & &
\end{tabular}

İskemik inme hastaları ele alınarak yapılan prognoz değerlendirmesinde 3.aylık mRs ile laktat arasında ilişki saptanmadı (Tablo 5)

Tablo 5. mRs ve Laktat arası ilişki

\begin{tabular}{lll}
\hline Değişkenler & mRs başvuru & mRs 3. ay \\
\hline Laktat (ilk başvuru) mmol/I & $\mathrm{p}=0,997, \mathrm{r}=0,001$ & $\mathrm{p}=0,696, \mathrm{r}=0,066$ \\
Laktat (24. Saat) mmol/l & $\mathrm{p}=0,264, \mathrm{r}=0,189$ & $\mathrm{p}=0,319, \mathrm{r}=0,168$ \\
\hline mRs: modifiye Ranson skalası, Spearman's test &
\end{tabular}

\section{Tartışma}

Çalışmamızın sonucu, kan laktat düzeyi ölçümünün hemorajik ve iskemik inmelerin ayırt edilmesinde ve iskemik inmelerde infarkt boyutunun belirlenmesinde laboratuvar parametresi olarak yardimc bir test olabileceğidir. Ancak laktatın, araştırmamıza alınan vaka örneklerine göre prognoz tayininde etkin bir laboratuvar parametresi olarak kullanımın faydalı olmayacağı tespit edildi.

Yakın zamanda yapılan çalışmalarda iskemik ve hemorajik inme gibi stres durumlarında, anaerobik metabolizma sonucu ortaya çıkan laktatın beyin tarafından enerji kaynağı olarak kullanıldığ 1 gösterilmiştir $(9,12,14)$. Artan laktat düzeyinin prognoz üzerine etkisi tartışmalıdır. Olumlu olduğunu gösteren çalışmaların yanı sıra olumsuz olduğunu gösteren çalışmalar mevcuttur $(8,10,12,15)$. Laktat düzeyinin, serebral mikrodiyaliz yöntemi ile elde edildiği bir çalışmada, hiperglikolitik süreç sonucu artan laktatın prognoz üzerine olumlu etkisi olduğu gösterilmiştir (15). Akut iskemik inme ve geçici iskemik atak hastalarında yapılan bir çalışmada, laktat düzeyi ölçümü kan ve serebrospinal sıvıdan yapılmıştır. Başvuru, 24. saat, 72. saat ve 7. gün bakılan kan laktat düzeyleri ile 3. ay mRs arasında korelasyon görülmezken, serebrospinal sıvıdan yapılan ölçümler ile 3. ay mRs arasında korelasyon görülmüştür (8). Bir hayvan deneyi çalışmasında, iskemik alana erken dönemde verilen ekzojen laktatın hücre ölümünden korunma, lezyon alanında küçülme ve iyi nörolojik sonlanım ile birlikteliği gösterilmiştir (16). Venöz kan laktat düzeyinin prognoz ile ilişkisinin araştırıldığ bir çalışmada $2 \mathrm{mmol} / \mathrm{L}$ üzerindeki başvuru kan laktat değeri hiperlaktatemi olarak kabul edilmiştir. Bu durumun 3 aylik mortalite ve kötü prognoz ile korele olduğu gösterilmiștir (13). Çalışmamızda başvuru ve 24. saat venöz kan laktat düzeylerine bakıldı. Hastaların takip edildikleri klinikte aldıkları tedaviye bağlı olarak, zamanla laktat düzeyinin azaldığ1 görüldü. $\mathrm{Bu}$ durum açısından, erkek ve kadın cinsiyet, iskemik ve hemorajik inme arasında anlamlı fark yoktu. Araştırmamızda venöz kan laktat düzeyleri ile mRs ve NIHSS arasındaki ilişki değerlendirildi. Tüm hastalar için laktat düzeyi ile mRs ve NIHSS arasında ve anlamlı bir ilişki tespit edilemedi.

Difüzyon MRG ile saptanan infarkt büyüklüğünün, $M R$ spektroskopi ile elde edilen doku laktat düzeyiyle ilişkisinin değerlendirildiği bir araştırmada, infarkt büyüklüğünün laktat düzeyi ile orantılı olarak 
arttığ tespit edilmiştir (17). Aynı yöntemle yapılan başka bir çalışmada artmış laktat/kolin oranı ile infarkt büyüklüğü arasında anlamlı ilişki gösterilmiştir (18). Bizim çalışmamızda da başvuru venöz kan laktat düzeyi ile infarkt büyüklüğü arasında benzer bir ilişki görüldü. Başvuru laktat düzeyleri, infarkt alanı MCA sulama alanının 2/3'ünden büyük olan grupta, 2/3'ünden küçük olan gruba göre daha yüksek tespit edildi.

Sınırlı sayıda klinik çalışmada subaraknoid kanama (SAK) ve artmış laktat düzeyi birlikteliği gösterilmiştir $(14,19)$. Bizim çalışmamızda da hemorajik inmelerde, iskemik inmelere göre laktat düzeyleri yüksek tespit edildi. Hemorajik inmeler kendi içinde değerlendirildiğinde ise başvuru ve 24 . saat laktat düzeyleri SAK'larda intraparankimal hemorajilere göre daha yüksek görüldü.

\section{Kisitlılıklar}

Çalışmaya sadece Eskişehir Osmangazi Üniversitesi acil servisine başvuran hastalar dahil edilmiştir ve 18 yaş atlı hastalar dışlanmıştır.

Daha önce yapılan bazı çalışmalarda laktat düzeyi kandan bakıldığında prognozla ilişkisi olmadığ 1 gösterilmiştir. Laktat düzeyi ölçümü için MR spektroskopi, mikrodiyaliz ve serebrospinal sıvı örneklemesi kullanıldığında ise prognozla ilişkili bulunmuştur. Bizim çalışmamızda laktat düzeyi için sadece venöz kan örneği kullanılmıştır.

Radyolojik görüntüleme yöntemi olarak başvuru anında tüm hastalar için BT kullanılırken, iskemik inmesi bulunanların büyük bir bölümünde ve hemorajik inmelerde

\section{REFERENCES}

1. Feigin VL, Lawes CMM, Bennett DA, Anderson CS. Stroke epidemiology: a review of populationbased studies of incidence, prevalence, and casefatality in the late 20th century. Lancet Neurol. $2003 ; 2: 43-53$

2. El-Saed Aiman, Kuller Lewis H., Newman Anne B., Lopez Oscar, Costantino Joseph, McTigue Kathleen, et al. Geographic Variations in Stroke Incidence and Mortality Among Older Populations görüntüleme yöntemi olarak $\quad$ MRG kullanılmamıştır.

Hastanemiz aynı zamanda inme merkezi olduğundan, özellikle trombolitik tedavi ve endovasküler girişim planlanan hastalar acil servisimize sevk edilmektedir. Örneklem büyüklüğü ve karakteri incelendiğinde özellikle inme alt gruplarında sayının ve homojenite yetersizliğinin sonuçlarımızı etkilemesi mümkündür.

Laktat düzeyi kullanılan ilaçlar (antidiyabetik ve hiperlipidemikler) ile de ilişkili olabilmektedir, karşılaştırma yapılırken kullanılan ilaçların venöz laktat üzerine etkisi incelenemedi.

Laktat düzeyi ile infarkt büyüklüğü ve inme tipi ilişkisi için, hasta sayısının yeterli olmaması nedeniyle bir ayrım değeri elde edilemedi.

\section{Sonuç}

İnme tipine göre, laktat düzeyleri arasındaki farktan dolayı, görüntülemenin geciktiği veya yapılamadığ 1 durumlarda laktat düzeyi acil tıp hekimlerine inme alt grubunu öngörmede yardımc1 olabilir.

İlk başvuru anında infarkt alanı büyüklüğü ile laktat düzeyi arasında korelasyon bulunması iskemik inmelerde infarkt alanının önceden tahmini açısından yardımcı olabilir. Bu durum tedavi stratejisini etkileyebilir.

Örneklem büyüklüğü ve homojenitesi ile laktat ölçüm yöntemi göz önünde bulundurularak konu ile ilgili daha ileri düzeyde çalışmaların yapılması gerektiği kanaatindeyiz. in Four US Communities. Stroke. 2006 Aug 1;37:1975-9.

3. Khosravani H, Shahpori R, Stelfox H, Kirkpatrick A, Laupland K. Occurrence and adverse effect on outcome of hyperlactatemia in the critically ill. Critical care. 2009;

4. Cerović O, Golubović V, Spec-Marn A, Kremzar B, Vidmar G. Relationship between injury severity and lactate levels in severely injured patients. Intensive Care Med. 2003;29:1300-5. 
5. Cevik AA, Dolgun H, Oner S, Tokar B, Acar N, Ozakin E, et al. Elevated lactate level and shock index in nontraumatic hypotensive patients presenting to the emergency department. Eur J Emerg Med. $2015 ; 22: 23-8$.

6. Nicoli F, Lefur Y, Denis B, Ranjeva JP, ConfortGouny S, Cozzone PJ. Metabolic counterpart of decreased apparent diffusion coefficient during hyperacute ischemic stroke: a brain proton magnetic resonance spectroscopic imaging study. Stroke. 2003;34:e82-87.

7. Predictive Value of Neurochemical Monitoring in Large Middle Cerebral Artery Infarction | Stroke [Internet]. [cited 2020 Sep 16]. Available from: https://www.ahajournals.org/doi/full/10.1161/01.st r.32.8.1863

8. Brouns R, Sheorajpanday R, Wauters A, De Surgeloose D, Mariën P, De Deyn PP. Evaluation of lactate as a marker of metabolic stress and cause of secondary damage in acute ischemic stroke or TIA. Clin Chim Acta. 2008 ;397:27-31.

9. Wyss MT, Jolivet R, Buck A, Magistretti PJ, Weber B. In Vivo Evidence for Lactate as a Neuronal Energy Source. J Neurosci. 2011; 18;31:7477-85.

10. New Evidence of Neuroprotection by Lactate after Transient Focal Cerebral Ischaemia: Extended Benefit after Intracerebroventricular Injection and Efficacy of Intravenous Administration - FullText - Cerebrovascular Diseases 2012, Vol. 34, No. 5-6 - Karger Publishers [Internet]. [cited 2020 Sep 16]. Availablefrom: https://www.karger.com/Article/Fulltext/343657

11. Cureton EL, Kwan RO, Dozier KC, Sadjadi J, Pal JD, Victorino GP. A different view of lactate in trauma patients: protecting the injured brain. J Surg Res. 2010;159:468-73.

12. T H, J K. Neuroprotective effects of lactate in brain ischemia: dependence on anesthetic drugs. Neurochem Int. 2013; 5;62:251-7.

13. Jo S, Jeong T, Lee JB, Jin YH, Yoon J, Jun YK, et al. Initial hyperlactatemia in the ED is associated with poor outcome in patients with ischemic stroke. Am J Emerg Med. 2012;30:449-55.

14. Oddo M, Levine JM, Frangos S, MaloneyWilensky E, Carrera E, Daniel RT, et al. Brain lactate metabolism in humans with subarachnoid hemorrhage. Stroke. 2012;43:1418-21.

15. Dienel GA. Brain lactate metabolism: the discoveries and the controversies. J Cereb Blood Flow Metab. 2012;32:1107-38.

16. Neuroprotective Role of Lactate after Cerebral Ischemia - Carole Berthet, Hongxia Lei, Jonathan Thevenet, Rolf Gruetter, Pierre J Magistretti, Lorenz Hirt, 2009 [Internet]. [cited 2020 Sep 17]. Available from: https://journals.sagepub.com/doi/10.1038/jcbfm.2 009.97

17. Associations Between Diffusion and Perfusion Parameters, N-Acetyl Aspartate, and Lactate in Acute Ischemic Stroke | Stroke [Internet]. [cited 2020 Sep 17]. Available from: https://www.ahajournals.org/doi/full/10.1161/stro keaha.108.525626

18. Persson L, Hillered L. Chemical monitoring of neurosurgical intensive care patients using intracerebral microdialysis. J Neurosurg. 1992 ;76:72-80.

19. Parsons MW, Li T, Barber PA, Yang Q, Darby DG, Desmond PM, et al. Combined (1)H MR spectroscopy and diffusion-weighted MRI improves the prediction of stroke outcome. Neurology. 2000;22;55:498-505. 